\title{
First detection of Corynebacterium ulcerans producing a diphtheria-like toxin in a case of human with pulmonary infection in the Rio de Janeiro metropolitan area, Brazil
}

\author{
AL Mattos-Guaraldi $/{ }^{+}$, JLM Sampaio ${ }^{1}$, CS Santos $/{ }^{2}$, FP Pimenta, GA Pereira, LGC Pacheco ${ }^{3}$, \\ A Miyoshi ${ }^{3}$, V Azevedo ${ }^{3}$, LO Moreira, FL Gutierrez ${ }^{4}$, JLF Costa ${ }^{4}$, R Costa-Filho ${ }^{4}$, PV Damasco/5, \\ TCF Camello, R Hirata Jr
}

\begin{abstract}
Faculdade de Ciências Médicas Universidade do Estado do Rio de Janeiro, Av. 28 de Setembro 87 - fundos, $3^{\circ}$ andar, Vila Isabel, 20551-030 Rio de Janeiro, RJ, Brasil ${ }^{1}$ Fleury Centro de Medicina Diagnóstica, São Paulo, SP, Brasil ${ }^{2}$ Instituto de Microbiologia Professor Paulo de Góes, Universidade Federal do Rio de Janeiro, Rio de Janeiro, RJ, Brasil ${ }^{3}$ Instituto de Ciências Biológicas, Universidade Federal de Minas Gerais, Belo Horizonte, MG, Brasil ${ }^{4}$ Hospital Procardíaco, Rio de Janeiro, RJ, Brasil ${ }^{5}$ Serviço de Doenças Infecciosas e Parasitárias, Universidade Federal do Estado do Rio de Janeiro, Rio de Janeiro, RJ, Brasil
\end{abstract}

The frequency and severity of human infections associated with Corynebacterium ulcerans appear to be increasing in different countries. Here, we describe the first $\mathrm{C}$. ulcerans strain producing a diphtheria-like toxin isolated from an elderly woman with a fatal pulmonary infection and a history of leg skin ulcers in the Rio de Janeiro metropolitan area.

Key words: Corynebacterium ulcerans - diphtheria-like toxin - human infection

Human infections with Corynebacterium ulcerans, including diphtheria, may be fatal and usually occur in adults with close animal contact (Wellinghausen et al. 2002, Lartigue et al. 2005). Some cases have no association with a farming community or the consumption of raw milk products, which suggests other routes of infection (De Zoysa et al. 2005). Patients may exhibit skin lesions that completely mimic cutaneous diphtheria or present as a tracheal-bronchial tree covered by pseudomembranes (Wagner et al. 2001, Dewinter et al. 2005). C. ulcerans infection may produce clinical syndromes in the lower respiratory tract (Dessau et al. 1995, Nureki et al. 2007), occasionally associated with signs of systemic inflammatory response syndrome and disseminated intravascular coagulation (Wellinghausen et al. 2005). C. ulcerans infections may occur in children previously immunized against diphtheria (Leek et al. 1990). Older urban adults may be also at risk for toxic complications due to waning immunity from remote or incomplete diphtheria immunization (Gubler et al. 1990, Wellinghausen et al. 2002). In some cases, it seems that C. ulcerans may induce severe infection in humans, depending on the immunological status of the patient rather than on the nature of the toxin (Lartigue et al. 2005).

C. ulcerans may harbour lysogenic-corynephages coding for the diphtheria toxin (DT), which is responsible for most of the systemic symptoms of diphtheria. Recent reports (Sing et al. 2003, 2005, Lartigue et al. 2005) suggest that DTs from Corynebacterium diph-

Financial support: CNPq, CAPES, Faperj, SR-2/UERJ, Pronex-MCT and Minas Gerais Genome Network (Fapemig).

+ Corresponding author: guaraldi@uerj.br

Received: 9 September 2007

Accepted: 5 June 2008 theriae and C. ulcerans are different and independent from any association with pharyngeal or extrapharyngeal disease. In contrast to $C$. diphtheriae (Nakao et al. 1996), unexpected sequence diversity in the tox gene has been observed among C. ulcerans human isolates. Independent of DT production, C. ulcerans was also found to produce clinical syndromes of the lower respiratory tract, such as pneumonia (Hommez et al. 1999, Hatanaka et al. 2003) and pulmonary granulomatous nodules (Dessau et al. 1995). Similar to non-toxigenic $C$. diphtheriae strains, which can also cause severe infections and have been considered an emerging infectious disease threat, the pathogenicity of C. ulcerans does not necessarily depend on the production of DT (Sing et al. 2003, 2005). As a consequence of increased awareness of potentially severe C. ulcerans infections, the following case of human infection associated with $C$. ulcerans came to the attention of the Laboratório de Difteria of Universidade do Estado do Rio de Janeiro for further bacterial differentiation and DT determination.

On July 24th 2000, an 80-year-old woman living in the metropolitan area of Rio de Janeiro was admitted to a local hospital with coma, shock and acute respiratory failure. Immediately after admission, the patient was intubated and received hemodynamic as well as mechanical respiratory support. On physical examination, she was bradycardic (pulse rate $\sim 60 \mathrm{bpm}$ ), hypotensive $(90 / 60 \mathrm{mmHg})$, and hypothermic $\left(34^{\circ} \mathrm{C}\right)$. Auscultation of the chest revealed diminished breath sounds. She presented signs of dental infection, but cultures from dental infectious sites were not performed. She had easily bleeding skin and chronic bilateral limb ulcers, all of which were covered by a yellowish membrane (Fig. 1). Her medical history was significant for receiving a diuretic for hypertension control and topic gentamicin treatment for at least one year for limb ulcers. From 4 - 10 days before hospitalization, she had two syncopal 


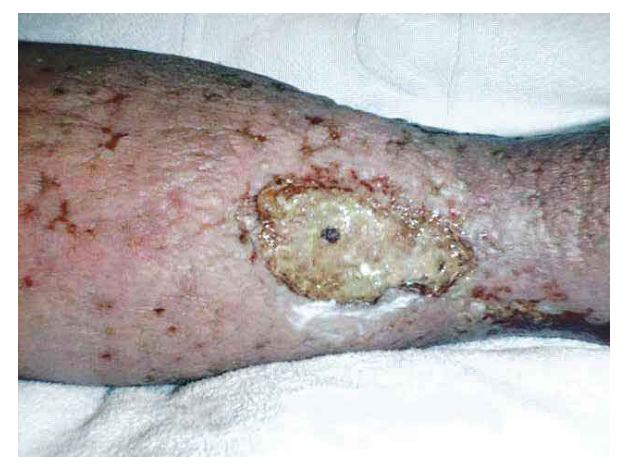

Fig. 1: skin ulcer covered by a yellowish membrane on leg of patient with Corynebacterium ulcerans infection.

episodes with no prodromic signs. Her immunization history for diphtheria was unknown. Blood, urine and bronchoalveolar lavage (BAL) samples and swabs from skin ulcers were obtained for microbiological analysis. Throat swabs were not taken. Chest X-ray on the first day showed bilateral pleural effusion (images not available). Bronchoscopy revealed an inflammatory process in left inferior bronchus. Computerized axial tomography (CT) confirmed large volume, bilateral pleural effusion (images not available), bronchopneumonia and alveolar collapses (atelectasis) in left lung base. ECG initially demonstrated a complete atrioventricular (3rd degree) blockade that reversed to atrial fibrillation after hemodynamic support. Echocardiogram showed moderate mitral insufficiency, normal ventricular function and bilateral atrial enlargement. Cranial CT scan showed parenchymal brain hemorrhage and microaneurysms. Abdominal ultrasound indicated presence of gallbladder calculus. Laboratory studies on the day of admission revealed anemia $\left(3.6 \times 10^{6} \mathrm{~mm}^{3}\right)$ and leucocytosis with a left shift: WBC count of $16.9 / \mathrm{mm}^{3}$ with $73 \%\left(12.333 / \mathrm{mm}^{3}\right)$ neutrophils and $9 \%\left(1.521 / \mathrm{mm}^{3}\right)$ band neutrophils. Serum concentration of C-reactive protein (CRP) increased from $8.4 \mathrm{mg} / \mathrm{dl}$ to $17.2 \mathrm{mg} / \mathrm{dl}$ during the first $48 \mathrm{~h}$ of hospitalization. The BAL specimen showed small grampositive rods within neutrophils resembling coryneform bacteria. Empirical parenteral antibiotic therapy was initiated with vancomycin, levofloxacin and amikacin. Cultures from the BAL revealed the presence of C. $u l$ cerans while cultures from blood, urine and skin lesions were negative. On August 1st, antimicrobial therapy was directed to $C$. ulcerans: amikacin and vancomycin were interrupted; levofloxacin intravenous therapy was maintained, and oral erythromycin was initiated. Topical treatment and débridement procedures resulted in complete healing of skin lesions. Cardiorespiratory symptoms worsened, and the patient developed acute renal failure. She received blood derivates, ventilation support and hemodialysis. On August 5th, toxigenicity tests performed by immunological methods showed positive results for the C. ulcerans clinical isolate. Diphtheria antitoxin (DAT) was subsequently administered, and only levofloxacin therapy was maintained. Signs of a systemic inflammatory reaction persisted after serotherapy.
On August 8th, hepatic and biliary functions worsened, and the patient underwent a videolaparoscopic cholecystectomy. Although subsequent blood, urine and BAL specimens gave negative results, new antibiotic therapy was started with cefepime, trimethoprim-sulfamethoxazole and sulbactam/ampicillin. After August 14th, the patient's condition became progressively worse. Pulmonary, cardiologic, renal and neurological examination showed evidence of multiple organ failures. The patient died on August 17th, and no autopsy was performed. As C. ulcerans was found in both BAL microscopy and culture, it is highly feasible that this bacterium induced respiratory failure and a systemic inflammatory reaction. Efforts to confirm the diagnosis of C. ulcerans infection in skin lesions by culture were complicated by the initiation of antibiotic treatment before a culture specimen had been obtained.

The patient lived in the Rio de Janeiro metropolitan area but any association with a farming community, consumption of raw dairy products, close contacts with animals or traveling activity were unknown. The source of infection for this case was undetermined.

Our study identified possible delays in seeking health care, diagnosing the illness, and initiating appropriate therapy. Diagnostic delay due to the non-specific nature of presenting features (extrapharyngeal infection) and the unusual nature of the pathogen (C. ulcerans) possibly contributed to patient's death. Moreover, diphtheria toxoid made of inactivated $C$. diphtheriae toxin as well as DAT might be less efficient at preventing infection due to C. ulcerans than C. diphtheriae (Sing et al. 2003, 2005).

Corynebacterium-like colonies were preliminarily characterized by Gram staining, colonial morphology, pigmentation and hemolysis and were identified by conventional biochemical assays and the semi-automatized API-Coryne System (BioMérrieux, Lyon, France) with system API web decoding (www.apiweb.biomerieux. com) (Mattos-Guaraldi \& Formiga 1998, Efstratiou \& George 1999). The C. ulcerans clinical isolate was API Code 0111326 and was positive for catalase, urease, gelatinase, alkaline phosphatase and $\alpha$-glycosidase. Nitrate, pyrazinamidase and esculin hydrolysis were negative. Fermentation tests were positive for glucose, maltose, ribose and glycogen. The presence of phospholipase D (Pld) was demonstrated by positive reverse CAMP test (i.e., inhibition of hemolysis by Staphylococcus aureus). Further bacterial identification was obtained by multiplex PCR assay targeting the 16S rRNA genes, rpoB and $p l d$, as described previously (Pacheco et al. 2007). This methodology allowed for rapid and accurate differentiation of C. ulcerans from closely related microorganisms, such as $C$. diphtheriae and Corynebacterium pseudotuberculosis (Fig. 2). Antimicrobial susceptibility was evaluated by the E-test (AB Biodisk, Solna, Sweden) as previously described (Martínez-Martínez et al. 1995). $S$. aureus breakpoints established by CLSI/NCCLS were considered for penicillin G (Martínez-Martínez et al. 1995, Sing et al. 2003, 2005, Lartigue et al. 2005, NCCLS 2005). The C. ulcerans clinical isolate was susceptible to imipenem, erythromycin, azithromycin, gentamicin, ciprofloxacin, rifampicin, tetracycline, chloramphenicol 


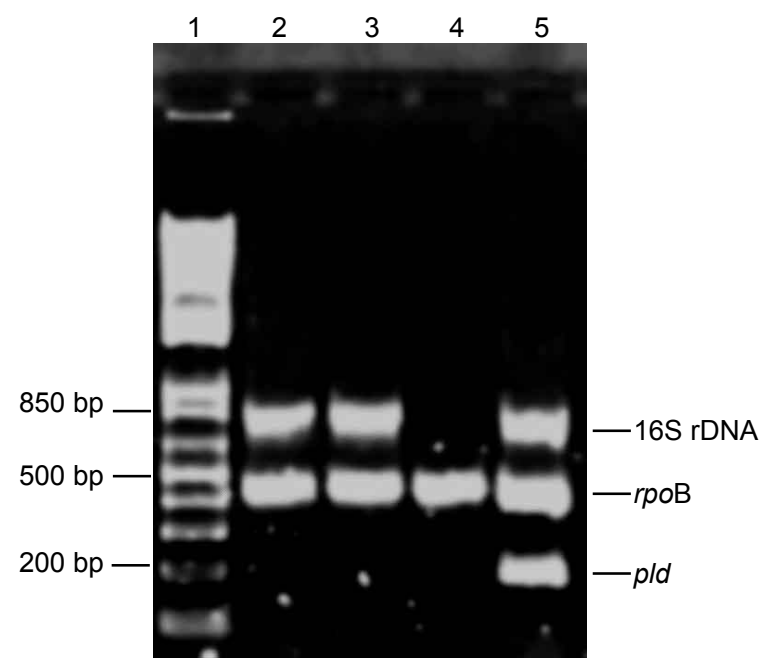

Fig. 2: agarose gel electrophoresis of multiplex PCR products. Lanes - 1: $1 \mathrm{~kb}$ Plus DNA Ladder; 2: Corynebacterium ulcerans control strain; 3: C. ulcerans clinical isolate; 4: Corynebacterium diphtheriae ATCC 27010; 5: Corynebacterium pseudotuberculosis CIP 102968.

and vancomycin. Like previous studies with $C$. diphtheriae complex, this $C$. ulcerans clinical isolate showed moderate susceptibility to penicillin G (MIC $0.19 \mathrm{mg} / \mathrm{l}$ ) and clindamycin (MIC $1.5 \mathrm{mg} / \mathrm{l}$ ) (Coyle et al. 1979, Gladin et al. 1999).

DT production was evaluated by the immunological Elek and Immunochromatographic strip-ICS tests (ICS strips were gently offered by Dr K Engler and Dr A Efstratiou, PHLS, London) (Efstratiou et al. 1998, Engler et al. 2002). Microorganisms were evaluated by "gold standard" Vero cell cytotoxicity assays (Efstratiou et al. 1998). PCR assays using primer sets for the C. diphtheriae tox gene were performed in triplicate based on protocols described elsewhere: Dt1, targeting fragment A (nt 43294) (Pallen et al. 1994); Dipht5 and Dipht7, targeting fragment B (nt 765-1032 and nt 1237-1525, respectively) (Nakao et al. 1996). Similar to some isolates of C. diphtheriae (Bonnet \& Begg 1999), C. ulcerans (Sing et al. 2003, 2005, Lartigue et al. 2005) may contain the tox gene without expressing biologically active DT. The geographical distribution of such strains remains unknown. In Europe, strains of $C$. ulcerans producing a DT-like toxin with differences within the B fragment (translocation and receptor binding domains) were related to diphtheria (Lartigue et al. 2005) and extrapharyngeal (deep skin ulceration on lower limb) human infections (Sing et al. 2003, 2005). The results of toxigenicity tests of this C. ulcerans human isolate were as follows: presence of DT gene by PCR, negative Elek test and slightly positive ICS. Moreover, the undiluted bacterial supernatant was unable to kill HeLa cells. Current results of toxigenicity tests are summarized in the Table. The C. ulcerans human isolate (809) showed positive and weak-positive results in the Elek and ICS tests, respectively. However, further evaluation of cytotoxicity by Vero cell assay showed the undiluted bacterial supernatant of the C. ulcerans 809 clinical isolate was unable to kill Vero cells. Conversely, the supernatant of the C. ulcerans CDC-KC279 control strain was toxic to the Vero cells at a titer of 1:5,120. The cell killing effect of both toxigenic C. ulcerans CDC-KC279 and C. diphtheriae CDCE8392 control strains was completely inhibited by the addition of DAT $(0.01 \mathrm{IU} / \mathrm{ml})$.

For the C. ulcerans 809 strain, the PCR test for detection of tox gene of $C$. diphtheriae using the Dt1 primer set (targeting fragment A) was negative whereas Dipht5 and Dipht7 primers sets (targeting fragment B) gave positive results (Fig. 3). Therefore, the C. ulcerans 809 human isolate produced a DT-like toxin with differences in fragment A and lack of toxic effect to Vero cells. These findings can partially explain the absence of typical clinical signs of DT, such as myocarditis and peripheral nerve damage.

Although diphtheria is thought to be declining in Brazil, only $30 \%$ of healthy individuals are fully protected against diphtheria in Rio de Janeiro, which indicates that the lack of immunity in older ( $>18$ years old) individuals remains a cause for concern (Damasco et al. 2005). The present case illustrates (i) C. ulcerans human infection may also occur in urban areas of developing countries where diphtheria remains endemic; (ii) C. ulcerans that produce diphtheria-like toxin may cause skin infections mimicking classical cutaneous diphtheria, thereby potentially providing a source of bacteria capable of causing life-threatening disease in the patient's environment; (iii) a better knowledge of taxonomy of coryneform bacteria, better identification schemes, greater awareness among clinicians and microbiologists of the importance of these microorganisms certainly will lead to an increased number of reports.

TABLE

Synopsis of toxigenicity tests results for C. ulcerans clinical isolate, C. ulcerans and C. diphtheriae control strains

\begin{tabular}{|c|c|c|c|c|c|c|c|}
\hline \multirow[b]{3}{*}{ Strain } & \multicolumn{7}{|c|}{ Results by indicated test } \\
\hline & \multicolumn{3}{|c|}{ tox $\mathrm{PCR}^{a}$} & \multirow[b]{2}{*}{ Elek } & \multirow[b]{2}{*}{ ICS } & \multirow[b]{2}{*}{ Vero cells } & \multirow[b]{2}{*}{ CAMP } \\
\hline & DT1 & Dipht5 & Dipht7 & & & & \\
\hline C. ulcerans human isolate 809 & - & + & + & + & $(+)$ & - & REV \\
\hline C. ulcerans CDC-KC279 & + & + & + & + & + & + & REV \\
\hline C. diphtheriae CDC-E8392 & + & + & + & + & + & + & - \\
\hline C. diphtheriae ATCC-27010 & - & - & - & - & - & - & - \\
\hline
\end{tabular}

$a$ : oligonucleotides targeting the fragment A (DT1) and the fragment B (Dipht5 and Dipht7) of the toxin gene; ICS: immunochromatographic strip; REV: reverse CAMP reaction; +: positive; $(+)$ : weak positive; -: negative. 
A

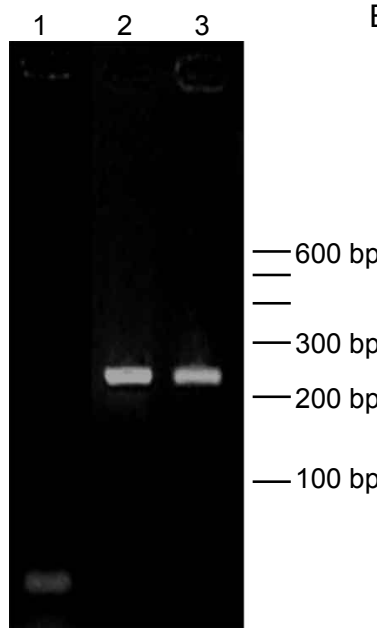

B

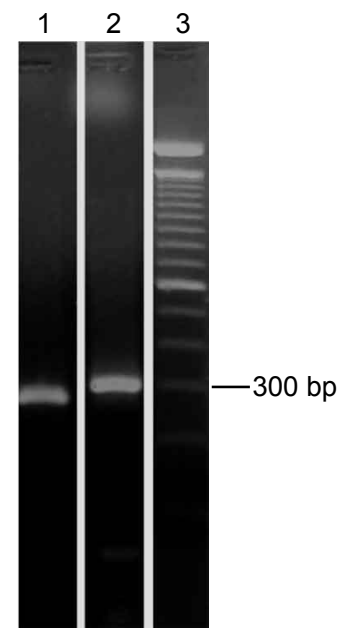

Fig. 3: agarose gel electrophoresis of PCR products. A: primer Dt1. Lanes 1: Corynebacterium ulcerans clinical isolate; 2: C. ulcerans CDC-KC279; 3: Corynebacterium diphtheriae CDC-E8392; B: primers Dipht5 and Dipht7, respectively. Lanes - 1, 2: C. ulcerans clinical isolate; 3: DNA marker.

In summary, we characterized the first case of $C . u l$ cerans associated with human infection in Brazil. This is one of the few cases to report slight differences in the DT produced by a strain of C. ulcerans.

\section{REFERENCES}

Bonnet JM, Begg NT 1999. Control of diphtheria: guidance for consultants in communicable disease control. Commun Dis Public Health 4: 242-249.

Coyle MB, Minshew BH, Bland JA, Hsu PC 1979. Erythromycin and clindamycin resistance in Corynebacterium diphtheriae from skin lesions. Antimicrob Agents Chemother 16: 525-527.

Damasco PV, Pimenta FP, Filardy AA, Brito SM, Andrade AF, Lopes GS, Hirata R Jr, Mattos-Guaraldi AL 2005. Prevalence of IgG diphtheria antitoxin in blood donors in Rio de Janeiro. Epidemiol Infect 133: 911-914.

Dessau RB, Brandt-Christensen M, Jensen OJ, Tonnesen P 1995. Pulmonary nodules due to Corynebacterium ulcerans. Eur Respir $J$ 8: 651-653.

Dewinter LM, Bernard KA, Romney MG 2005. Human clinical isolates of Corynebacterium diphtheriae and Corynebacterium ulcerans collected in Canada from 1999 to 2003 but not fitting reporting criteria for cases of diphtheria. J Clin Microbiol 43: 3447-3449.

De Zoysa A, Hawkey PM, Engler K, George R, Mann G, Reilly W, Taylor D, Efstratiou A 2005. Characterization of toxigenic Corynebacterium ulcerans strains isolated from humans and domestic cats in the United Kingdom. J Clin Microbiol 43: 4377-4381.

Efstratiou A, Engler KH, Dawes CS, Sesardic D 1998. Comparison of phenotypic and genotypic methods for detection of DT among isolates of pathogenic corynebacteria. J Clin Microbiol 36: 3173-3177.

Efstratiou A, George RC 1999. Laboratory guidelines for the diagnosis of infections caused Corynebacterium diphtheriae and Corynebacterium ulcerans. Commun Dis Public Health 2: 251-257.

Engler KH, Efstratiou A, Norn D, Kozlov RS, Selga I, Glushkevich
TG, Tam M, Melnikov VG, Mazurova IK, Kim VE, Tseneva GY, Titov LP, George RC 2002. Immunochromatographic strip test for rapid detection of diphtheria toxin: description and multicenter evaluation in areas of low and high prevalence of diphtheria. J Clin Microbiol 40: 80-83.

Gladin DP, Koslova NS, Zaitseva TK, Cherednichenko AS, Khval SA 1999. Sensitivity of Corynebacterium diphtheriae isolated in Saint Petersburg to antibacterial drugs. Antibiot Khimioter 44: 17-21.

Gubler JG, Wust J, Krech T, Hany A 1990. Classical pseudomembranous diphtheria caused by Corynebacterium ulcerans. Schweiz Med Wochenschr 120: 1812-1816.

Hatanaka A, Tsunoda A, Okamoto M, Ooe K, Nakamura A, Miyakoshi M, Komiya T, Takahashi M 2003. Corynebacterium ulcerans diphtheria in Japan. Emerg Infect Dis 9: 752-753.

Hommez J, Devriese LA, Vaneechoutte M, Riegel P, Butaye P, Haesebrouck F 1999. Identification of nonlipophilic corynebacteria isolated from dairy cows with mastitis. J Clin Microbiol 37: 954-957.

Lartigue MF, Monnet X, Le Fleche A, Grimont PA, Benet JJ, Durrbach A, Fabre M, Nordmann P 2005. Corynebacterium ulcerans in an immunocompromised patient with diphtheria and her dog. J Clin Microbiol 43: 999-1001.

Leek MD, Sivaloganathan S, Devaraj SK, Zamiri I, Griffiths GD, Green MA 1990. Diphtheria with a difference - a rare Corynebacterium fatality with associated apoptotic cell death. Histopathology 16: 187-189.

Martínez-Martínez L, Ortega MC, Suárez AI 1995. Comparison of ETest with broth micro dilution and disk diffusion for susceptibility testing of coryneform bacteria. J Clin Microbiol 33: 1318-1321.

Mattos-Guaraldi AL, Formiga LCD 1998. Bacteriological properties of a sucrose fermenting Corynebacterium diphtheriae strain isolated from a case of endocarditis. Curr Microbiol 37: 156-158.

Nakao H, Pruckler JM, Mazurova IK, Narvskaia OV, Glushkevich T, Marijevski VF, Kravetz AN, Fields BS, Wachsmuth IK, Popovic T 1996. Heterogeneity of diphtheria toxin gene, tox, and its regulatory element, $d t x R$, in Corynebacterium diphtheriae strains causing epidemic diphtheria in Russia and Ukraine. J Clin Microbiol 34: 1711-1716.

NCCLS - National Committee for Clinical Laboratory Standards 2005. Performance Standards for Antimicrobial Disk Susceptibility Tests, 8th ed. Approved Standard Document M2-A8, NCCLS, Wayne, p. 44-51.

Nureki S, Miyazak E, Matsuno O, Takenaka R, Ando M, Kumamoto T, Nakano T, Ohkusu K, Ezaki T 2007. Corynebacterium ulcerans infection of the lung mimicking the histology of ChurgStrauss Syndrome. Chest 131: 1237-1239.

Pacheco LGC, Pena RR, Castro TLP, Dorella FA, Bahia RC, Carminati R, Frota MN, Oliveira SC, Meyer R, Alves FS, Miyoshi A, Azevedo V 2007. Multiplex PCR assay for identification of Corynebacterium pseudotuberculosis from pure cultures and for rapid detection of this pathogen in clinical samples. J Med Microbiol 56: 480-486.

Pallen MJ, Hay AJ, Puckey LH, Efstratiou A 1994. Polymerase chain reaction for screening clinical isolates of corynebacteria for the production of diphtheria toxin. J Clin Pathol 47: 353-356.

Sing A, Bierschenk S, Heesemann J 2005. Classical diphtheria caused by Corynebacterium ulcerans in Germany: aminoacid sequence differences between diphtheria toxins from Corynebacterium diphtheriae and Corynebacterium ulcerans. Clin Infect Dis 40: 325-326. 
Sing A, Hogardt M, Bierschenk S, Heesemann J 2003. Detection of differences in the nucleotide and amino acid sequences of diphtheria toxin from Corynebacterium diphtheriae and Corynebacterium ulcerans causing extrapharyngeal infections. $J$ Clin $\mathrm{Mi}$ crobiol 41: 4848-4851.

Wagner J, Ignatius R, Voss S, Hopfner V, Ehlers S, Funke G, Weber
U, Hahn H 2001. Infection of the skin caused by Corynebacterium ulcerans and mimicking classical coetaneous diphtheria. Clin Infect Dis 33: 1598-1600.

Wellinghausen N, Sing A, Kern WV, Perner S, Marre R, Rentschler $\mathrm{J}$ 2002. A fatal case of necrotizing sinusitis due to toxigenic Corynebacterium ulcerans. Int J Med Microbiol 292: 59-63. 